\title{
ASSESSMENT OFTHE KNOWLEDGE OF HEALTHCARE PROFESSIONALS ABOUT RHEUMATOID ARTHRITIS IN A TERTIARY SERVICE IN THE CITY OF TEFÉ, AM.
}

Wuerles Bessa Barbosa ${ }^{1,}$

1.Secretaria Municipal de Saúde de Manaus, Manaus (AM), Brazil.

*Corresponding author: wuerlesbessa@gmail.com

\section{BACKGROUND}

Rheumatoid arthritis (RA) is a chronic, inflammatory autoimmune disease characterized by synovitis that can evolve with bone erosions and irreversible deformities. It mainly affects women between 30 and 50 years of age. In this context, this study aimed to evaluate the sociodemographic profile of employees of a tertiary service located in the city of Tefé, Amazonas.

\section{METHODS}

The present work is a cross-sectional observational study with 45 employees of a tertiary health care service. Concepts, epidemiology and clinical behavior of RA were presented, as well as the main treatment models discussed.

\section{RESULTS}

Thirty-two employees participating in the project are female, mainly trained by nursing technicians. The average age of health professionals was $45 \pm 5$ years, and most work on a 12 -hour shift ( $80 \%$ of cases). Sixty percent of collaborators did not know the main symptoms of RA and 70\% reported ignorance of extra-articular manifestations, such as vasculitis and pericarditis.

\section{CONCLUSION}

As the work was developed, it can be concluded that health education is essential for the development and updating of the knowledge of professionals who work in health institutions, such as hospitals, clinics and basic health units, actively related to screening and early diagnosis of patients with RA.

\section{KEYWORDS}

Rheumatoid arthritis, Health education, Health professionals, Amazon. 